\title{
Continuous positive airway pressure improves respiratory mechanics and efficiency of neural drive in stable COPD: an exploratory study
}

\author{
Kai Wang ${ }^{1,2 \#}$, Zhen-Yu Liang ${ }^{3 \#}$, Xi-Long Wang ${ }^{1 \#}$, Yun $\mathrm{Li}^{4 \#}$, Yi-Rong Lu ${ }^{1}$, Jun-Fang Liu ${ }^{1}$, Jia-Hui Li ${ }^{1}$, \\ Li-Mei Xu' ${ }^{1}$, Guo-Qiang Chen ${ }^{1}$, Ping Chang ${ }^{2}$, Zhong-Ran Cen ${ }^{2}$, Xin Chen ${ }^{1}$ \\ ${ }^{1}$ Department of Pulmonary and Critical Care Medicine, Zhujiang Hospital, Southern Medical University, Guangzhou 510282, China; ${ }^{2}$ Department \\ of Critical Care Medicine, Zhujiang Hospital, Southern Medical University, Guangzhou 510282, China; ${ }^{3}$ Department of Respiratory Medicine, \\ The State Key Laboratory of Respiratory Disease, National Clinical Research Center for Respiratory Disease, Guangzhou Institute of Respiratory \\ Health, First Affiliated Hospital of Guangzhou Medical University, Guangzhou 510120, China; ${ }^{4}$ Department of Respiratory Medicine, Gaozhou \\ People's Hospital, Guangdong 525200, China \\ Contributions: (I) Conception and design: X Chen, K Wang, Y Li; (II) Administrative support: None; (III) Provision of study materials or patients: X \\ Chen, P Chang, ZR Cen; (IV) Collection and assembly of data: K Wang, YR Lu, JF Liu; (V) Data analysis and interpretation: Y Li, JH Li, LM Xu, \\ GQ Chen; (VI) Manuscript writing: All authors; (VII) Final approval of manuscript: All authors. \\ \#These authors contributed equally to this work. \\ Correspondence to: Xin Chen. Department of Pulmonary and Critical Care Medicine, Zhujiang Hospital, Southern Medical University, Guangzhou \\ 510282, China. Email: chen_xin1020@163.com; Zhong-Ran Cen. Department of Critical Care Medicine, Zhujiang Hospital, Southern Medical \\ University, Guangzhou 510282, China. Email: cenzhr2014@163.com.
}

Background: Continuous positive airway pressure (CPAP) is a major treatment strategy for severe chronic obstructive pulmonary disease (COPD), especially with respiratory failure. However, it remains inconclusive whether CPAP affects respiratory mechanics and neural drive in stable COPD patients without respiratory failure.

Methods: Twenty-two COPD patients without respiratory failure received CPAP starting from 4 to $10 \mathrm{cmH}_{2} \mathrm{O}$ in $1 \mathrm{cmH}_{2} \mathrm{O}$ increments. Respiratory pattern, end expiatory lung volume (EELV), dynamic PEEPi $\left(\right.$ PEEPi $\left._{\text {dyn }}\right)$, airway resistance (Raw), pressure-time product of diaphragmatic pressure (PTPdi) and esophageal pressure (PTPeso), root mean square (RMS) of diaphragm electromyogram (EMGdi) and ratio of ventilation (Ve) to EMGdi (i.e., Ve/RMS) were measured before and at each level of continue positive airway pressure (CPAP). A subgroup analysis was performed between patients with and without inspiratory muscle weakness.

Results: Nineteen patients completed the treatment. The respiratory pattern improved significantly after CPAP. Raw, PTPdi, and Pdi decreased significantly. $\triangle$ EELV decreased at $4 \mathrm{cmH}_{2} \mathrm{O}(\mathrm{P}<0.05)$, but increased significantly at $>8 \mathrm{cmH}_{2} \mathrm{O}$. $\mathrm{PEEPi}_{\text {dyn }}$ decreased from $2.18 \pm 0.98$ to $1.37 \pm 0.55 \mathrm{cmH}_{2} \mathrm{O}$. RMS increased while Ve/RMS improved significantly after CPAP $(\mathrm{P}<0.05)$. Besides, CPAP could significantly improve respiratory mechanics in patients with inspiratory muscle weakness.

Conclusions: CPAP improves respiratory pattern, PEEPi, Raw, work of breathing and efficiency of neural drive in COPD patients without respiratory failure, but easily increases dynamic pulmonary hyperinflation. These effects on respiratory mechanics are significant in patients with inspiratory muscle weakness.

Keywords: Chronic obstructive pulmonary disease (COPD); continuous positive airway pressure; respiratory mechanics; neural respiratory drive

Submitted Jul 17, 2019. Accepted for publication Dec 23, 2019.

doi: $10.21037 /$ jtd.2019.12.120

View this article at: http://dx.doi.org/10.21037/jtd.2019.12.120 


\section{Introduction}

Persistent airflow limitation is a key characteristic of chronic obstructive pulmonary disease (COPD) (1). The severity of COPD is usually associated with delayed diagnosis (2), and progression of COPD is based on a number of abnormalities in respiratory mechanics, including the development of intrinsic positive end-expiratory pressure (PEEPi) and dynamic pulmonary hyperinflation (DPH) (1). As known, PEEPi and DPH may increase inspiratory threshold load and work of inspiratory muscle, leading to low mechanical efficiency of the diaphragm, and ultimately, respiratory failure (RF) (3). Bi-level positive pressure ventilation (BiPAP) and continuous positive pressure ventilation (CPAP) represent the major treatment strategy for RF-complicated COPD $(4,5)$. In particular, CPAP has been proven to effectively improve the respiratory function in this subset of patients (6).

In a cohort of nine subjects, O'Donoghue et al. indicated that CPAP could reduce PEEPi and work of breathing, and affect neural drive slightly in severe stable COPD with RF (7). For non-RF-complicated COPD, CPAP was shown to significantly improve patient survival, and risk of hospital admission in those who also had obstructive sleep apnea (OSA) $(8,9)$. But so far, few studies, if any, have been done to explore the impacts of CPAP on respiratory mechanics in non-RF-complicated COPD. It remains unclear whether these impacts differ from RFcomplicated COPD. In addition, while the neural drive may be altered in COPD patients with RF who frequently suffer severe hypercapnia (10) and may thus respond to subsequent use of CPAP, the impact on neural drive by CPAP remains inadequately elucidated among non-RFcomplicated COPD without hypoxemia and hypercapnia.

Since CPAP is therapeutically beneficial for COPD patients with $\mathrm{RF}(6,11,12)$, we hypothesized that CPAP may also ameliorate the abnormal respiratory mechanics in non-RFcomplicated COPD. In this study, we explored the influence of CPAP on respiratory mechanics and neural drive in stable COPD patients without RF. Given the close association of DPH and PEEPi with inspiratory muscle activity, the potential effects of CPAP were also compared between subjects with and without inspiratory muscle weakness.

\section{Methods}

\section{Subjects}

Twenty-two males with moderate to severe COPD from respiratory outpatient clinic of Zhujiang Hospital, Southern Medical University were enrolled in this study between January 1st, 2018 and December 31st, 2018. The diagnoses in these subjects were determined according to 2017 GOLD (1). All patients were confirmed to be with stable COPD and without acute exacerbation in the previous month. None of the patients had respiratory failure [arterial carbon oxygen tensions $\left(\mathrm{PaO}_{2}\right)<60 \mathrm{mmHg}$ with or without carbon dioxide tension $\left(\mathrm{PaCO}_{2}\right)>50 \mathrm{mmHg}$, acute or chronic respiratory diseases except COPD, and comorbidities with musculoskeletal, neuromuscular, or cardiovascular disorders that could interfere with the measurements in this study. Continued use of prescribed medications for COPD, including inhaled bronchodilators, was allowed. Informed consents were signed and obtained from all subjects. The protocol was approved by the Zhujiang Hospital Ethics Committee and registered on https://register.clinicaltrials.gov (identifier: NCT02285400).

\section{Protocol}

The diaphragm electromyogram (EMGdi) was recorded using multipair esophageal electrode catheter which consisted of 10 coils or five recording electrode pairs (Figure 1). Each electrode was $2.0 \mathrm{~mm}$ in diameter and $1.0 \mathrm{~cm}$ by length. Five consecutive recording pairs were formed, with an inter-electrode distance of $3 \mathrm{~cm}$ within each pair. The catheter was advanced through nasal meatus and nasopharynx before being swallowed into the esophagus. The optimal position of the catheter was confirmed when the largest EMGdi signals were recorded from pair 1 and pair 5 with the smallest EMGdi from pair 3 (Figure 1). The catheter was then secure. The EMGdi signals were amplified by a bio-amplifier (FE224, ADInstruments, Australia), with the band-pass filter set between 20 and $1,000 \mathrm{~Hz}$, with notch filter set at $50 \mathrm{~Hz}$. All signals were record by a high-performance data acquisition device (Powerlab 16/35; ADInstruments, Australia).

Gastric pressure (Pgas) and esophageal pressure (Peso) were recored using two balloons mounted on the multipair esophageal electrode catheters. When electrode coil NO.5 approached the diaphragm, the two balloons were positioned at the stomach and mid-esophagus, respectively. Satisfactory positioning of the balloons was further confirmed by pushing on the abdomen or by the sniff maneuver. The esophageal balloon was filled with $0.5 \mathrm{~mL}$ of air and the gastric balloon was filled with $1.0 \mathrm{~mL}$ of 
A

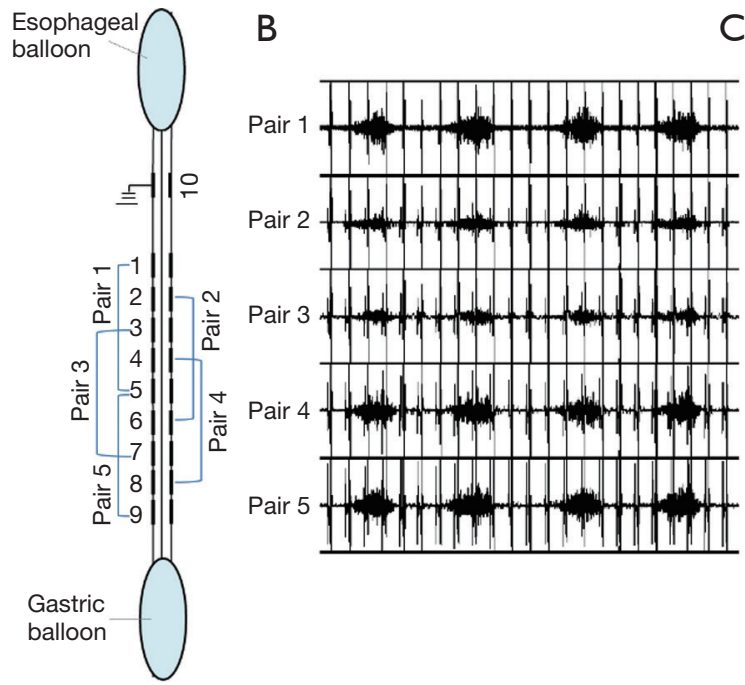

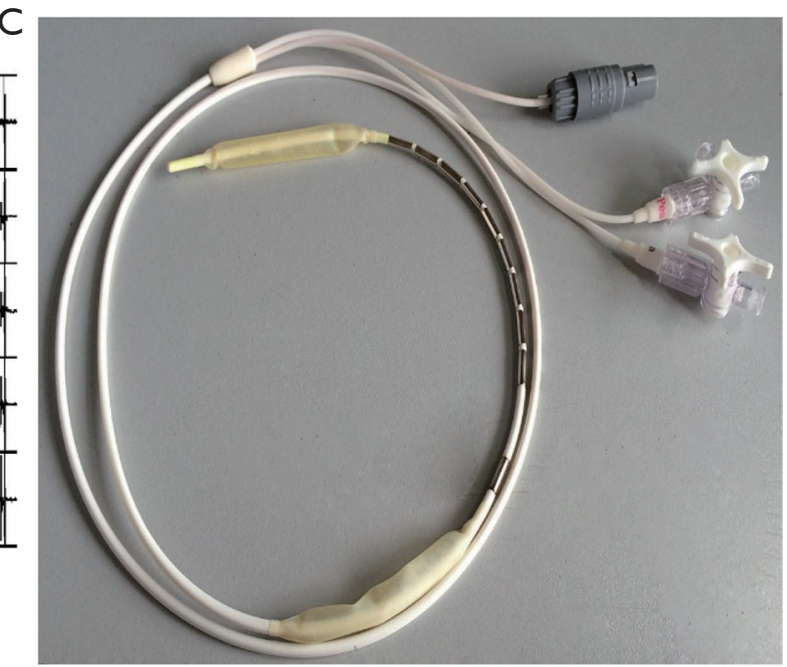

Figure 1 Multipair esophageal electrode catheter with esophageal and gastric pressure balloons. (A) Configuration of electrode; (B) diaphragmatic EMG (EMGdi) recorded from multipair esophageal electrode after electrode catheter was optimally positioned, characterized by largest EMGdi signals from pair 1 and pair 5, the smallest EMGdi was recorded from pair 3; (C) photograph of multipair esophageal electrode catheter.

air. Peso and Pgas, and trans-diaphragmatic pressure (Pdi; calculated by subtracting Peso from Pgas) were measured with a physiological press transducer (MLT844; ADInstruments, Australia). The flow rate was obtained by using a pressure differential pneumotachograph (MLT300L; ADInstruments, Australia). The Noninvasive ventilator (BiPAP Synchrony, Respironic, USA) was applied using CPAP model and connected to the pressure differential pneumotachograph by ventilator tube.

When starting the experiment, all participants were trained to practice the following maneuvers: slow deep respiration, maximum sniff efforts at functional residual capacity (FRC), maximal is volumetric contraction at FRC, and maximal inspiration from FRC to total lung capacity (TLC). After resuming stable breaths, the next 30 breaths were recorded for analysis. CPAP was then conducted and gradually increased from 4 to $10 \mathrm{cmH}_{2} \mathrm{O}$ in increments of $1 \mathrm{cmH}_{2} \mathrm{O}$. At each CPAP level, the patients breathed for a 5 -minute stabilization period. The air flow, baseline pressure and the diaphragm electromyogram (EMGdi) were also rechecked at each increase. The data from eight stable breaths were acquired for analysis. End-tidal carbon dioxide pressure $\left(\mathrm{PetCO}_{2}\right)$ and saturation of pulse oxygen $\left(\mathrm{SpO}_{2}\right)$ were measured synchronously by Vital Signs Monitor (NT1D12100065, Newtech Electronics, USA).

\section{Data analysis}

The acquisition of flow and pressure was performed at a sampling rate of $200 \mathrm{~Hz}$, and that of diaphragmatic EMG, $1,000 \mathrm{~Hz}$. The flow record was used to calculate respiratory rate (RR), mean respiratory cycle time (Ttot), tidal volume $(\mathrm{Vt})$, inspiratory capacity(IC), inspiratory time (Ti), inspiratory flow $(\mathrm{Vt} / \mathrm{Ti})$, inspiratory duty cycle (Ti/Ttot) and inspired minute ventilation $(\mathrm{Ve})$.

Dynamic intrinsic positive expiratory end pressure $\left(\mathrm{PEEPi}_{\mathrm{dyn}}\right)$ was calculated from the decrease in Peso negative pressure before inspiratory flow generation. Pressure-time product of Pdi (PTPdi) was calculated as the time integration of Pdi during pulmonary volume variation per minute. Airway resistance (Raw) was calculated as the ratio of tidal variations in transpulmonary pressure $(\Delta \mathrm{Pl})$ and flow at the midpoint of inspiratory (i.e., Raw $=$ $\Delta \mathrm{Pl} /$ flow). The variation of end-expiratory lung capacity $(\triangle \mathrm{EELV})$ was evaluated by detecting changes in inspiratory capacity (IC). The changes of IC were calculated by the difference between the baseline IC of steady breathing and the IC measured at each different CPAP levels. Root mean square (RMS) of EMG was created off-line with a time constant of $100 \mathrm{~ms}$ and calculated automatically by the LabChart7.5 software. The maximum RMS was 
Table 1 Patient characteristics

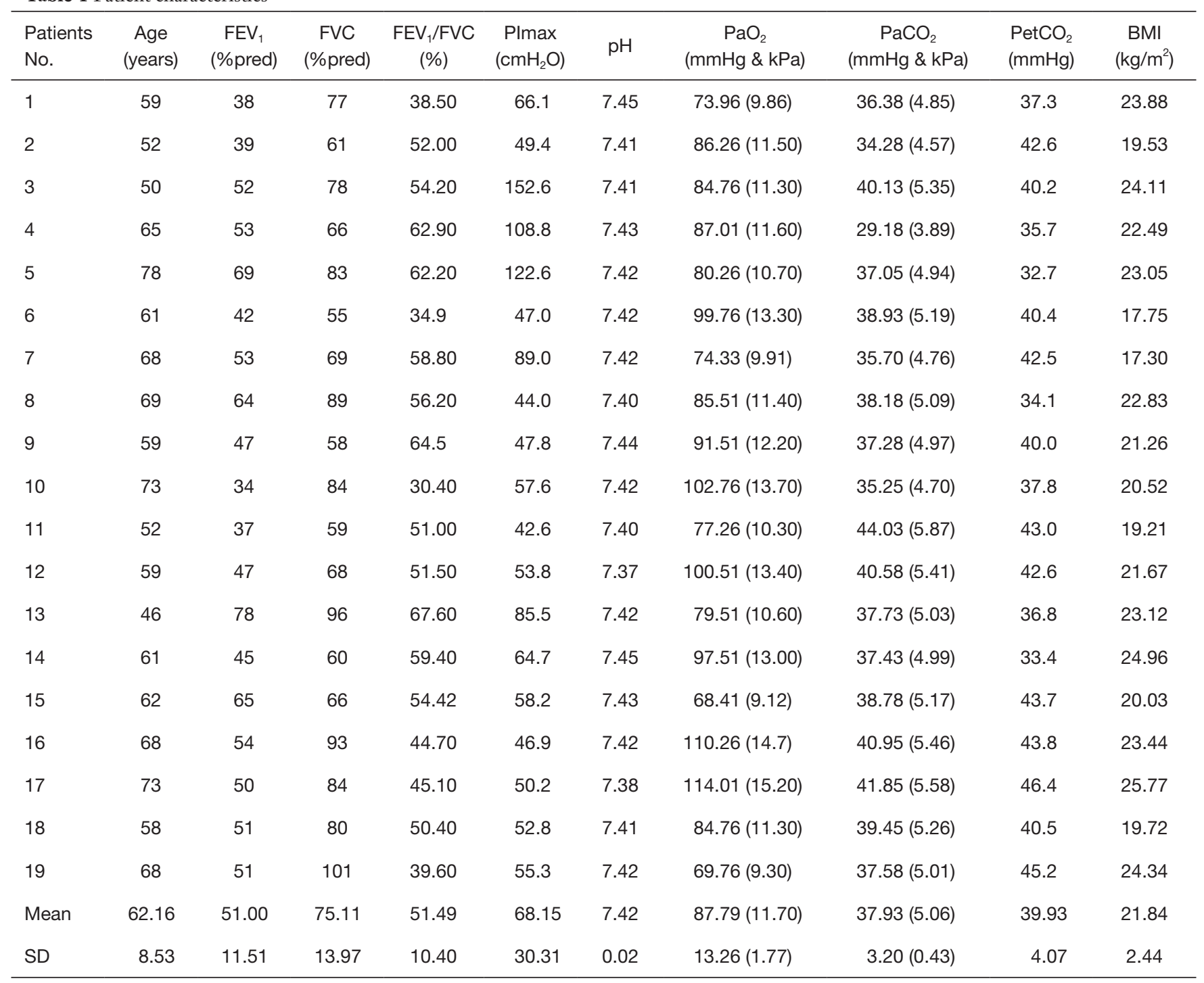

FVC, forced vital capacity; FEV1, forced expiratory volume in 1 second; \%pred, percent predicted; PImax, maximal inspiratory pressure; $\mathrm{PaCO}_{2}, \mathrm{PaO}_{2}$, arterial carbon dioxide and oxygen tensions; $\mathrm{PetCO}_{2}$, end tidal carbon dioxide pressure; BMI, body mass index.

dynamically selected from all five electrode pairs with the largest EMG amplitude for each breathing cycle. To avoid the interference of the electrocardiogram (ECG), RMS was measured from segments between QRS complexes. The EMG data are expressed as the mean of maximun values obtained during wakefulness among eight maximal inspiratory maneuvers from functional residual capacity to total lung capacity. Efficiency of neural respiratory drive was presented as the ratio of ventilation to the EMGdi (i.e., Ve/RMS). The intensity of dyspnea was evaluated by using modified Borg scores at baseline and at the end of each CPAP level.

\section{Statistics}

The statistical analyses were performed using Statistical Package for the Social Sciences version 19.0 software (IBM Corp., Armonk, NY, USA). Patient characteristics at baseline showing in Tables 1,2 were presented as actual value and mean \pm standard deviation (SD). The value of other tables and figures were described as mean \pm standard error (SE). Data was examined by repeated measures analysis of variance (ANOVA) with the Greenhouse-Geisser adjustment for multisample asphericity. Differences between CPAP levels were compared using the unpaired t-test. The baseline 
Table 2 Effects of different CPAP on central drive, ventilation-drive coupling in COPD patients

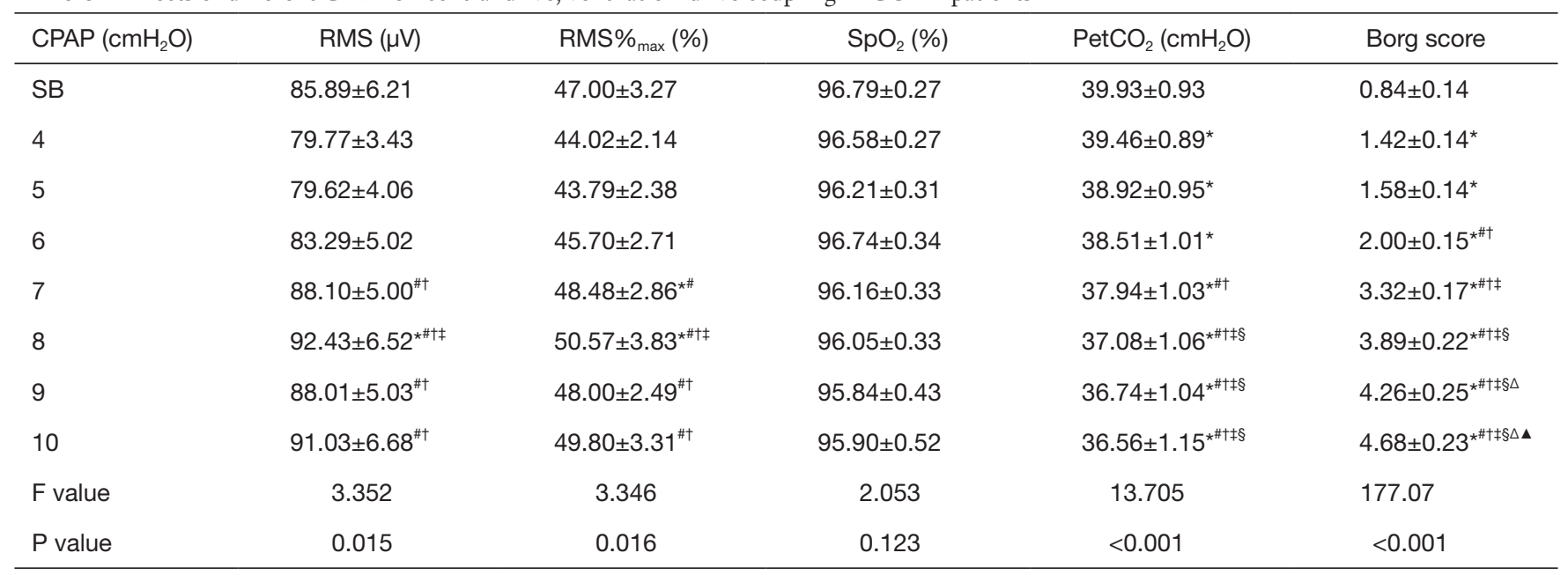

Data are presented as mean \pm SE unless otherwise stated; $\mathrm{P}$ results of repeated analysis of variance (ANVOA) comparison between different CPAP levels; * $\mathrm{P}<0.05$ vs. steady breathing; ${ }^{\mathrm{P}} \mathrm{P}<0.05$ vs. $4 \mathrm{cmH}_{2} \mathrm{O}$ level; ${ }^{\dagger} \mathrm{P}<0.05$ vs. $5 \mathrm{cmH}_{2} \mathrm{O}$ level; ${ }^{\ddagger} \mathrm{P}<0.05$ vs. $6 \mathrm{cmH}_{2} \mathrm{O}$; ${ }^{\S} \mathrm{P}<0.05$ vs. $7 \mathrm{cmH}_{2} \mathrm{O}$ level; ${ }^{\stackrel{ }{ } \mathrm{P}<0.05}$ vs. $8 \mathrm{cmH}_{2} \mathrm{O}$ level; ${ }^{\Delta} \mathrm{P}<0.05$ vs. $9 \mathrm{cmH}_{2} \mathrm{O}$ level. $\mathrm{CPAP}$, continue positive airway pressure; RMS, root mean square of diaphragm electromyogram; $\mathrm{SPO}_{2}$, pulse oxygen saturation; PetCO ${ }_{2}$, end tidal carbon dioxide pressure; $\mathrm{SB}$, stable breathing.

differences between subgroups were compared using unpaired t-test. Subgroup analyses in Figure 2 were performed using repeated measures ANOVA with Greenhouse-Geisser adjustment. A value of $\mathrm{P}<0.05$ was statistically significant.

\section{Results}

Among the 22 patients initially included, three patients dropped out due to intolerance of the esophageal electrodes. The remaining 19 patients successfully completed the study were all male. The baselines of the patients are revealed in Table 1.

The RR, Vt, Ve, Vt/Ti, and Ti/Ttot significantly increased along with CPAP levels (all $\mathrm{P}<0.05$ ). The Ttot and Ti progressively decreased during CPAP application $(\mathrm{P}<0.05)$. The comparisons of these parameters across different levels are in Table 3.

There was a descending-ascending trend in Raw, which fell from $14.09 \pm 1.60 \mathrm{cmH}_{2} \mathrm{O} / \mathrm{L} / \mathrm{s}$ at $0 \mathrm{cmH}_{2} \mathrm{O}$ to $9.58 \pm$ $0.70 \mathrm{cmH}_{2} \mathrm{O} / \mathrm{L} / \mathrm{s}$ at $7 \mathrm{cmH}_{2} \mathrm{O}$, but later increased to $11.52 \pm 0.73 \mathrm{cmH}_{2} \mathrm{O} / \mathrm{L} / \mathrm{s}$ at $10 \mathrm{cmH}_{2} \mathrm{O}$. The Pdi and PTPdi/ min were maximally reduced to $25.19 \pm 2.19 \mathrm{cmH}_{2} \mathrm{O}$ and $9.49 \pm 1.11 \mathrm{cmH}_{2} \mathrm{O} \cdot \mathrm{s}$ at 10 and $8 \mathrm{cmH}_{2} \mathrm{O}$ respectively $(\mathrm{P}<0.05)$. The IC increased from $2.33 \pm 0.11$ to $2.49 \pm 0.12 \mathrm{~L}$ at $4 \mathrm{cmH}_{2} \mathrm{O}$, but decreased gradually after $8 \mathrm{cmH}_{2} \mathrm{O}(\mathrm{P}<0.05)$. Compared with IC, the $\triangle \mathrm{EELV}$ showed the opposite change: it was reduced at $4 \mathrm{cmH}_{2} \mathrm{O}$ and increased after $8 \mathrm{cmH}_{2} \mathrm{O}$ $(\mathrm{P}<0.05)$. The $\mathrm{PEEPi}_{\text {dyn }}$ was significantly reduced during
CPAP $(\mathrm{P}<0.001)$. The lowest value was achieved at $8 \mathrm{cmH}_{2} \mathrm{O}$ (Table 4, Figure 3).

The maximal RMS of EMGdi $\left(\mathrm{RMS}_{\text {max }}\right.$ ) was recorded during maximal inspiration from FRC to TLC in all patients to correct RMS and Ve/RMS. There was no change in RMS at low CPAP levels $(\mathrm{P}>0.05)$. But it increased gradually after $6 \mathrm{cmH}_{2} \mathrm{O}(\mathrm{P}<0.05)$. The ratio of ventilation to the EMGdi (i.e., Ve/RMS) increased significantly with the increment in CPAP levels $(\mathrm{P}>0.05)$. The corrected RMS and Ve/RMS were the same with RMS and Ve/RMS (Table 2, Figure 3). The Borg score increased gradually, and $\mathrm{PetCO}_{2}$ decreased, during CPAP $(\mathrm{P}<0.05)$. No significant change in $\mathrm{SPO}_{2}$ was found $(\mathrm{P}>0.05)$.

\section{Effects of CPAP on patients with inspiratory muscle weakness}

A subgroup analysis was performed to determine the effects of CPAP on patients with and without inspiratory muscle weakness. Thus, based on inspiratory muscle strength, patients were allocated to two subgroups. The inspiratory muscle weakness was defined as a $\mathrm{PI}_{\max }<60 \mathrm{cmH}_{2} \mathrm{O}$. No significant differences were found at baseline in all parameters, except $\mathrm{PI}_{\max }, \mathrm{Peso}_{\max }, \mathrm{Pdi}_{\max }$ and $\mathrm{PetCO}_{2}$ $(\mathrm{P}<0.05)$ between patients with $(\mathrm{n}=12)$ and without inspiratory muscle weakness $(\mathrm{n}=7)$ (Table 5).

During CPAP, $\Delta$ Raw, $\Delta$ Pdi, $\Delta$ PTPdi, $\Delta \mathrm{PEEPi}_{\text {dyn }}, \Delta \mathrm{VE}$, $\Delta \mathrm{EELV}, \Delta \Delta \mathrm{RMS}, \Delta \mathrm{Ve} / \mathrm{RMS}, \Delta \mathrm{Borg}$ and $\Delta \mathrm{SPO}_{2}$ did not differ between two groups at the same level, as shown in 

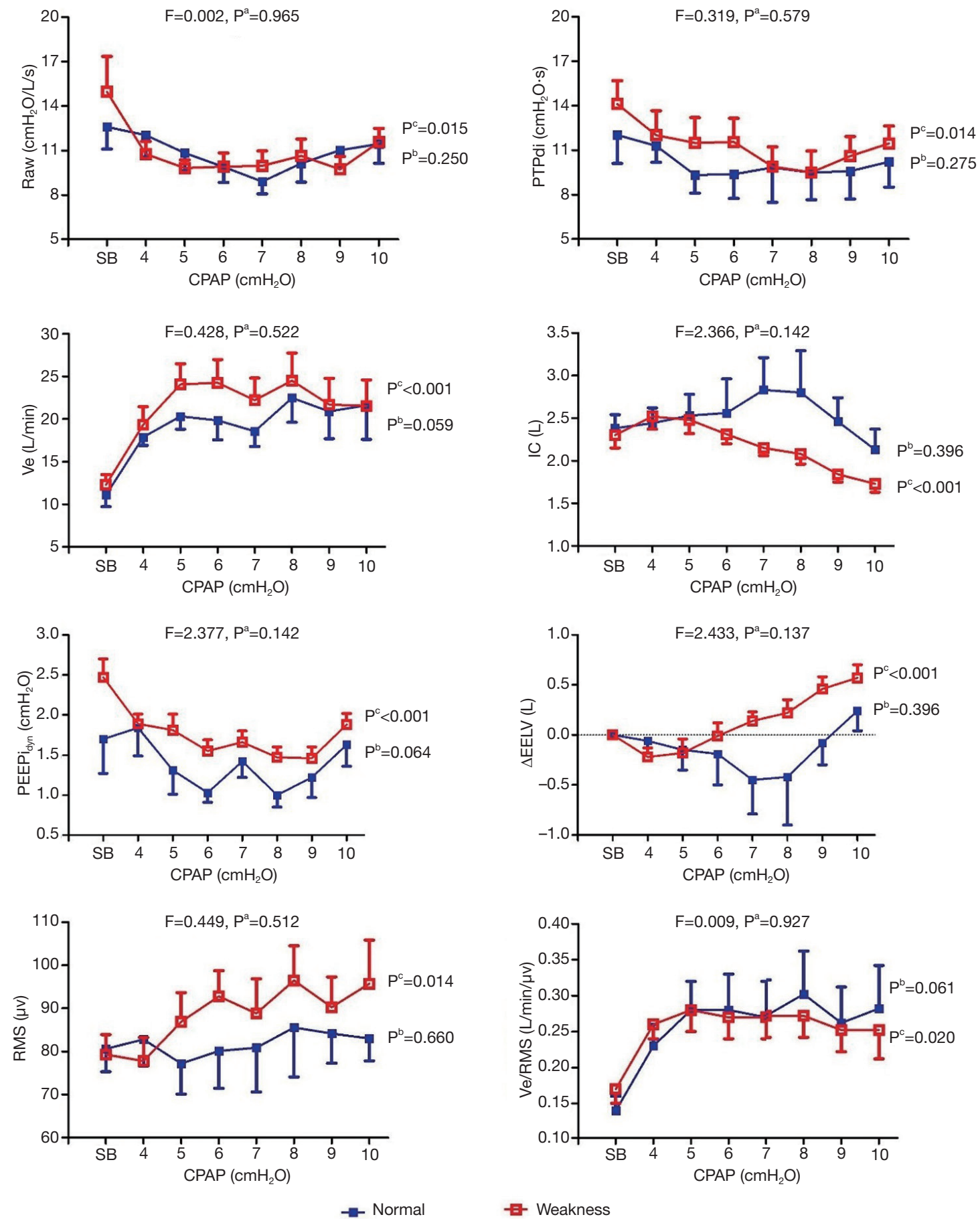

Figure 2 The trend of airway resistance, work of breathing during CPAP at different levels between patients with and without inspiratory muscle weakness. The data are presented as the mean \pm standard error (SE) unless otherwise indicated. $\mathrm{P}^{\mathrm{a}}$ : the results of a repeated measures analysis of variance (ANOVA) comparison of the normal group versus the weakened group (i.e., between-group effects); $\mathrm{P}^{\mathrm{b}}$ : results of the repeated measures analysis of variance (ANOVA) comparison of the normal group at different levels (i.e., within-subject group); $\mathrm{P}^{c}$ : the results of the repeated measures analysis of variance (ANOVA) comparison of the weakened group at different levels (i.e., within-subject group). COPD, chronic obstructive pulmonary disease; CPAP, continuous positive airway pressure; Raw, airway resistance; $\mathrm{PTP}_{\mathrm{di}}$, pressuretime product of diaphragmatic pressure.; Ve, minutes volume; IC, inspiratory capacity; $\mathrm{PEEP}_{\mathrm{dyn}}$, dynamic intrinsic positive end-expiratory pressure; $\triangle \mathrm{EELV}$, change in end expiratory lung volume; RMS, root mean square of diaphragm electromyogram. 
Table 3 Effects of different CPAP levels on breathing pattern in COPD patients

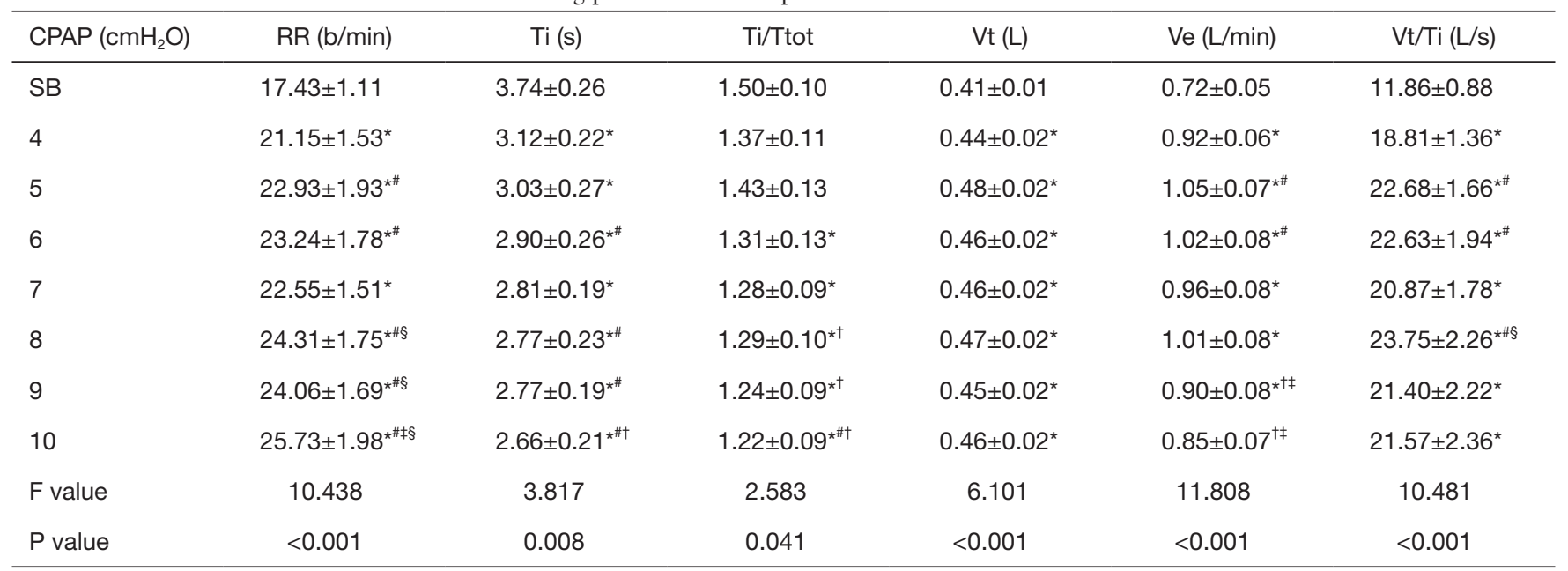

Data are presented as mean $\pm \mathrm{SE}$ unless otherwise stated; $\mathrm{P}$ results of repeated analysis of variance (ANVOA) comparison between different CPAP levels; ${ }^{\star} \mathrm{P}<0.05$ vs. steady breathing; ${ }^{\#} \mathrm{P}<0.05$ vs. $4 \mathrm{cmH}_{2} \mathrm{O}$ level; ${ }^{\dagger} \mathrm{P}<0.05$ vs. $5 \mathrm{cmH}_{2} \mathrm{O}$ level; ${ }^{\ddagger} \mathrm{P}<0.05$ vs. $6 \mathrm{cmH} \mathrm{O}_{2} \mathrm{O}$; ${ }^{\S} \mathrm{P}<0.05$ vs. $7 \mathrm{cmH}_{2} \mathrm{O}$ level; ${ }^{\Delta} \mathrm{P}<0.05$ vs. $8 \mathrm{cmH}_{2} \mathrm{O}$ level; ${ }^{\Delta} \mathrm{P}<0.05$ vs. $9 \mathrm{cmH}_{2} \mathrm{O}$ level. CPAP, continue positive airway pressure; RR, respiratory rate; Ttot, respiratory cycle time; $\mathrm{Ti}$, inspiratory time; Ti/Ttot, inspiratory duty ratio; $\mathrm{Vt}$, tidal volume; Ve, minute ventilation; $\mathrm{Vt} / \mathrm{Ti}$, inspiratory flow; $\mathrm{SB}$, stable breathing.

Table 4 Effects of different CPAP on airway resistance and work of breathing in COPD patients

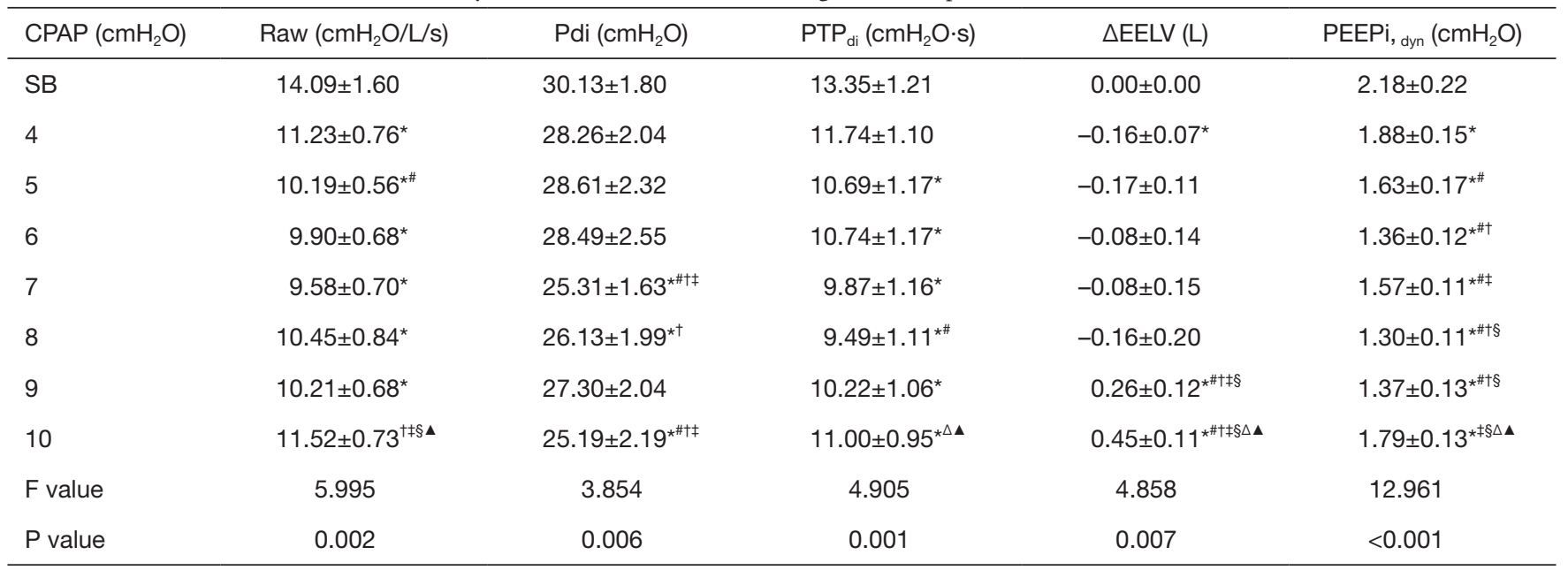

Data are presented as mean \pm SE unless otherwise stated; $\mathrm{P}$ results of repeated analysis of variance (ANVOA) comparison between different CPAP levels; ${ }^{*} \mathrm{P}<0.05$ vs. steady breathing; ${ }^{\#} \mathrm{P}<0.05$ vs. $4 \mathrm{cmH}_{2} \mathrm{O}$ level; ${ }^{\dagger} \mathrm{P}<0.05$ vs. $5 \mathrm{cmH}_{2} \mathrm{O}$ level; ${ }^{\ddagger} \mathrm{P}<0.05$ vs. $6 \mathrm{cmH}_{2} \mathrm{O}$; ${ }^{\S} \mathrm{P}<0.05$ vs. $7 \mathrm{cmH}_{2} \mathrm{O}$ level; ${ }^{\wedge} \mathrm{P}<0.05$ vs. $8 \mathrm{cmH}_{2} \mathrm{O}$ level; ${ }^{\wedge} \mathrm{P}<0.05$ vs. $9 \mathrm{cmH}_{2} \mathrm{O}$ level. CPAP, continue positive airway pressure; Raw, airway resistance; Pdi, trans-diaphragmatic pressure; PTPdi, pressure-time product of diaphragmatic pressure; IC, Inspiratory capacity; $\triangle E E L V$, Changes in end expiratory lung volume; PEEPi, dyn, dynamic intrinsic positive end-expiratory pressure. SB, stable breathing.

Figure 2 (all $\mathrm{P}>0.05$ ). In addition, there were no significant improvements in these parameters at different CPAP levels in patients without inspiratory muscle weakness. In those with inspiratory muscle weakness, CPAP was found to improve their respiratory pattern, Raw, PTPdi, PEEPi $\mathrm{d}_{\mathrm{dyn}}$, and VE/RMS (all $\mathrm{P}<0.05$ ). Among them, the Vt/Ti and
RMS were increased, and the value of $\triangle E E L V$ changed from negative to positive after $6 \mathrm{cmH}_{2} \mathrm{O}(\mathrm{P}<0.05)$.

\section{Discussion}

The present study demonstrated that, in non-RF- 

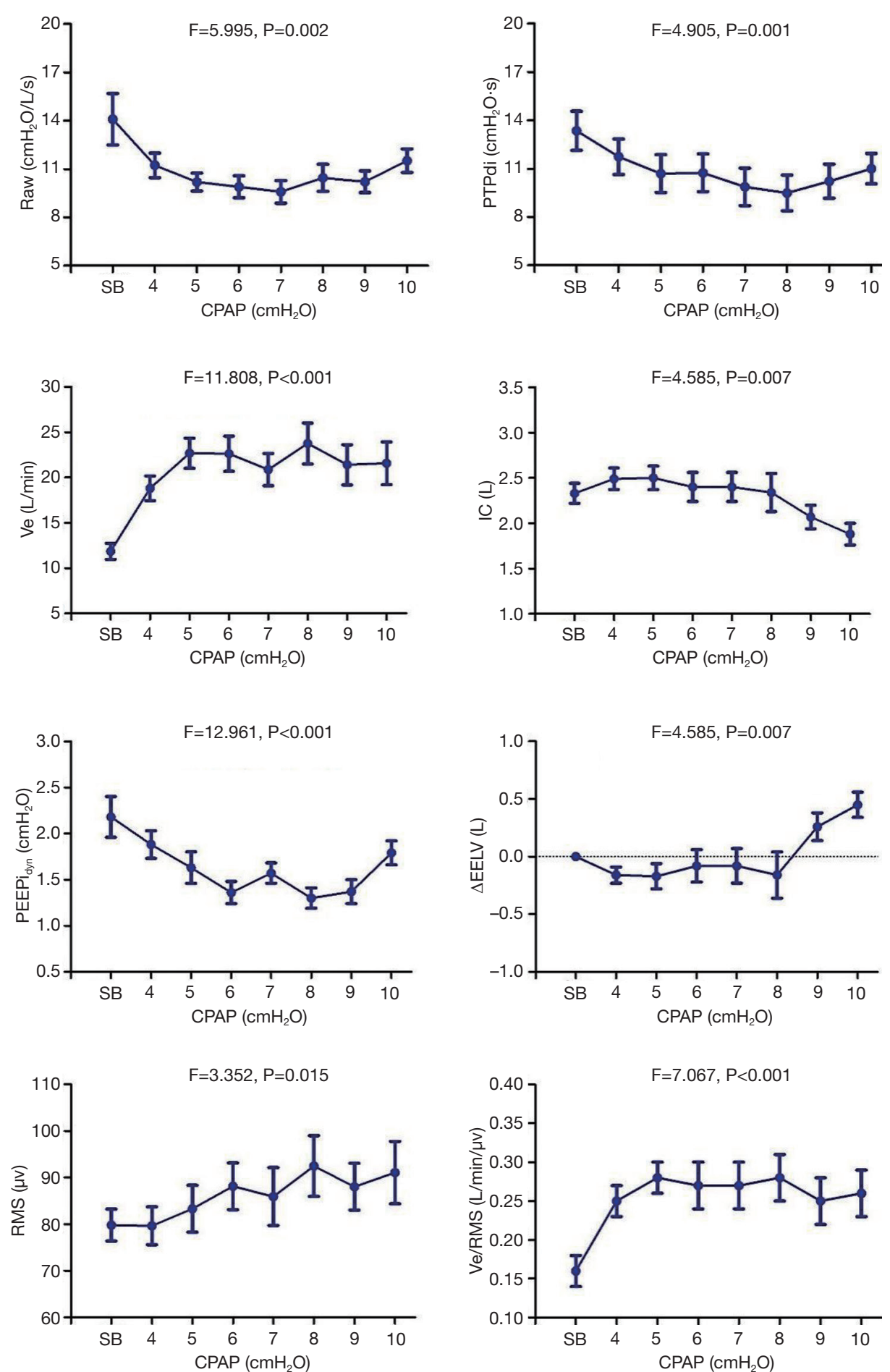

Figure 3 The trend of Raw, PTPdi, Ve, IC, PEEPidyn, EELV, RMS, Ve/RMS during CPAP at different levels. The data are presented as the mean \pm standard error (SE) unless otherwise indicated. $\mathrm{P}$, the results of repeated measures analysis of variance (ANOVA). COPD, chronic obstructive pulmonary disease; CPAP, continuous positive airway pressure; Raw, airway resistance; $\mathrm{PTP}_{\mathrm{di}}$, pressure-time product of diaphragmatic pressure.; Ve, minutes volume; IC, inspiratory capacity; $\mathrm{PEEP}_{\mathrm{dyn}}$, dynamic intrinsic positive end-expiratory pressure; $\triangle \mathrm{EELV}$, change in end expiratory lung volume; RMS, root mean square of diaphragm electromyogram. 
Table 5 Different indices between two subgroups during normal respiration

\begin{tabular}{|c|c|c|c|c|}
\hline Parament & $\begin{array}{l}\text { Normal respiratory muscle group } \\
\qquad(\mathrm{n}=7)\end{array}$ & $\begin{array}{l}\text { Weakened respiratory muscle group } \\
\qquad(\mathrm{n}=12)\end{array}$ & $\mathrm{t}$ & $P$ \\
\hline $\mathrm{PI}_{\max }\left(\mathrm{cmH}_{2} \mathrm{O}\right)$ & $98.46 \pm 12.01$ & $50.47 \pm 1.48$ & -3.965 & 0.007 \\
\hline FVC pred (\%) & $75.57 \pm 11.96$ & $74.83 \pm 11.53$ & 0.108 & 0.915 \\
\hline $\mathrm{FEV}_{1} \%$ pred (\%) & $55.43 \pm 13.72$ & $48.42 \pm 9.71$ & 1.306 & 0.209 \\
\hline $\operatorname{Pmo}\left(\mathrm{cmH}_{2} \mathrm{O}\right)$ & $-0.82 \pm 0.25$ & $-0.53 \pm 0.11$ & -1.229 & 0.236 \\
\hline Peso $\left(\mathrm{cmH}_{2} \mathrm{O}\right)$ & $-9.74 \pm 1.22$ & $-12.73 \pm 1.23$ & 1.604 & 0.127 \\
\hline Pga $\left(\mathrm{cmH}_{2} \mathrm{O}\right)$ & $18.43 \pm 2.33$ & $20.03 \pm 1.60$ & -0.583 & 0.568 \\
\hline $\operatorname{Raw}\left(\mathrm{cmH}_{2} \mathrm{O} / \mathrm{L} / \mathrm{s}\right)$ & $12.59 \pm 1.49$ & $14.96 \pm 2.39$ & -0.707 & 0.489 \\
\hline $\mathrm{RR}(\mathrm{b} / \mathrm{min})$ & $15.10 \pm 1.53$ & $18.79 \pm 1.41$ & -1.689 & 0.109 \\
\hline Ttot (s) & $4.27 \pm 0.46$ & $3.43 \pm 0.29$ & 1.643 & 0.119 \\
\hline $\mathrm{Ti}(\mathrm{s})$ & $1.75 \pm 0.16$ & $1.35 \pm 0.10$ & 2.241 & 0.039 \\
\hline Ti/Ttot & $0.41 \pm 0.01$ & $0.40 \pm 0.01$ & 0.692 & 0.498 \\
\hline $\mathrm{Vt}(\mathrm{L})$ & $0.75 \pm 0.08$ & $0.71 \pm 0.07$ & 0.325 & 0.749 \\
\hline $\mathrm{Ve} / \mathrm{RMS}(\mathrm{L} / \mathrm{min} / \mu \mathrm{V})$ & $0.14 \pm 0.02$ & $0.17 \pm 0.02$ & -0.731 & 0.475 \\
\hline PTPdi & $12.02 \pm 1.92$ & $14.12 \pm 1.57$ & -0.831 & 0.417 \\
\hline PTPeso & $-8.83 \pm 0.90$ & $-9.11 \pm 0.78$ & 0.223 & 0.827 \\
\hline PEEPi & $1.69 \pm 0.43$ & $2.47 \pm 0.23$ & -1.753 & 0.098 \\
\hline $\mathrm{PetCO}_{2}\left(\mathrm{cmH}_{2} \mathrm{O}\right)$ & $36.94 \pm 1.33$ & $41.68 \pm 0.97$ & -2.910 & 0.010 \\
\hline $\mathrm{SPO}_{2}(\%)$ & $97.14 \pm 0.46$ & $96.58 \pm 0.34$ & 0.995 & 0.334 \\
\hline
\end{tabular}

Data are presented as mean \pm SD unless otherwise stated; $\mathrm{P}$ results of independent sample $\mathrm{t}$ test between normal respiratory muscle group and weakened respiratory muscle group. PImax, maximal inspiratory pressure; FVC, forced vital capacity; FEV1, forced expiratory volume in 1 second; \%pred, percent predicted; Pmo, mouth pressure; Peso, esophageal pressure Pga, gastric pressure; Pdi, transdiaphragmatic pressure; Raw, airway resistance; RR, respiratory rate; Ttot, respiratory cycle time; Ti, inspiratory time; Ti/Ttot inspiratory duty ratio; Vt, tidal volume; Ve, minute ventilation; Vt/Ti, inspiratory flow; IC, inspiratory capacity; RMS, root mean square of diaphragm electromyogram; PTPeso, pressure-time product of esophageal pressure; PTPdi, pressure-time product of diaphragmatic pressure; $\mathrm{PEEPi}$, intrinsic positive end expiratory pressure; $\mathrm{PetCO}_{2}$, end tidal carbon dioxide pressure; $\mathrm{SPO}_{2}$, pulse oxygen saturation. 
complicated COPD patients, CPAP could improve the respiratory pattern, reduce Raw and PEEPi, lower the inspiratory threshold and muscle effort, and increase the efficiency of the neural drive. The neural drive was increased with increments of CPAP levels. The end-expiratory lung capacity was reduced at a low CPAP level $\left(4 \mathrm{cmH}_{2} \mathrm{O}\right)$ and then elevated when CPAP exceeded $8 \mathrm{cmH}_{2} \mathrm{O}$. Furthermore, CPAP could offer extra benefit in COPD patients with inspiratory muscle weakness, but meanwhile easily increase the DPH.

Different from the study by O'Donoghue in RFcomplicated COPD (7), we found that, as CPAP increased, the lung volume significantly decreased at a low pressure level $\left(4 \mathrm{cmH}_{2} \mathrm{O}\right)$ and remained stable until the pressure exceeded $8 \mathrm{cmH}_{2} \mathrm{O}$. It was not observed in the former study where the lung volume increased persistently. Besides, the Raw and work of breathing initially decreased and then gradually increased after $8 \mathrm{cmH}_{2} \mathrm{O}$ in our cohort, in contrast to the continuous reduction in RF-complicated COPD. We also revealed a gradual increase in RMSdi which was previously reported not to change significantly (7).

In this research, Raw and work of breathing decreased early in CPAP and then gradually increased after $8 \mathrm{cmH}_{2} \mathrm{O}$. CPAP may reduce Raw, because it can support large airways such as the trachea or bronchi, and reopen the occluded small airways $(<2 \mathrm{~mm})$. In addition, PEEPe can counteract endogenous PEEPi, which would make the alveoli easier to expand, and finally decrease airway resistance. However, high level PEEPe could excessively expand the alveoli and aggravate lung hyperinflation. Because of hyperinflation, a further increase in inspiratory pressure would not cause a corresponding increase in flow rate. Therefore, tidal volume would fluctuate due to Raw (calculated as $\Delta \mathrm{Pl} /$ flow).

PTPeso and PTPdi correlate well with diaphragmatic oxygen consumption, and reflect the work of breathing (13). Our study showed that PTPeso and PTPdi initially decreased and later increased along with CPAP increments. These findings were consistent with changes in airway resistance. After applying CPAP, PEEPe could decrease the difference between mouth pressure and PEEPi, and therefore reduce the work of inspirator. However, when the pressure is excessively high, the work of the diaphragm would be increased. High pressure may aggravate lung hyperinflation, and therefore increase airway resistance. In addition, lung hyperinflation could also decrease the curvature of the diaphragm and interfere with the optimal length-tension relationship (14), and result in low exercise capacity (15). More oxygen would be needed for the work of diaphragm with higher diaphragmatic tension.

The change in the neural respiratory drive (NRD) has been used to evaluate the efficacy of several drugs $(16,17)$, and to predict the risk of acute exacerbation of COPD (18). Noninvasive positive pressure ventilation (NPPV) is to overcome airway resistance and improve ventilation, thereby reduce the work of breathing and the burden on the respiratory muscle, and facilitate sufficient rest of fatigued respiratory muscle $(19,20)$. The NRD should theoretically be decreased under NPPV. However, we found that RMS increased gradually with increased CPAP, which indicated that NRD also increased gradually. We speculated that the increased CPAP level would gradually aggravate lung hyperinflation and lead the diaphragm to a worse position.

Previous studies have shown that the NRD was controlled and regulated by the mechanical characteristics of the diaphragm (14,21-24), and were higher in chronic obstructive pulmonary disease patients than healthy subjects, and related to disease severity (25). When diaphragmatic fibers maintain a good length-tension relationship, the electrical activity of diaphragm would be at a fairly low level. By contrast, when these fibers are not at an optimal initial length (e.g., shortened), the diaphragm may not properly exert its mechanical properties and may show increased diaphragmatic electrical activity.

IC was gradually increased with CPAP levels increased to $8 \mathrm{cmH}_{2} \mathrm{O}$, which indicated the releasing of $\mathrm{DPH}$ in our study. But when CPAP continually raised, the DPH turned aggravation, which would cause the diaphragm to move downwards. In this manner, the gradual deterioration of the length-tension relationship of diaphragm fibers could result in abnormal electrical activity. But the study of O'Donoghue FJ demonstrated that EMGdi remained stable in severe COPD patients with respiratory failure (7). The reason for the different findings of EMGdi maybe that the patients of O'Donoghue study were more severe, that may exist $\mathrm{CO}_{2}$ retention, hypoxemia, or diaphragmatic fatigue.

The efficiency of NRD in patients without respiratory failure has not been evaluated yet. In the present study, the efficiency of NRD was presented as the ratio of ventilation to the EMGdi (Ve/RMS) (26). Ve/RMS initially increased, and then decreased at $8 \mathrm{cmH}_{2} \mathrm{O}$. The reason may be that low-level CPAP could reduce airway resistance and inspiratory effort, which increases the efficiency of NRD. However, a high CPAP level could increase the DPH, which would require greater NRD to produce the same changes in diaphragmatic pressure (27). In addition, the increased DPH would decrease the contractility of diaphragm, while 
neuromuscular uncoupling would deteriorate even further. In our study, the NRD was increased at a high CPAP level, meanwhile the tidal volume and minute ventilation decreased gradually. As we had known, NRD could provide a useful physiological biomarker for breathlessness in COPD and closely relate to the intensity of exertional breathlessness (28). In our study, the Borg score was greatly increasing after $7 \mathrm{cmH}_{2} \mathrm{O}$, which was consistent with the changes of RMS. These demonstrated that a high CPAP level may decrease the efficiency of NRD.

Persistent air flow limitation and increased inspiratory threshold may cause diaphragmatic fatigue, while weakening respiratory muscle function $(29,30)$. In our results, CPAP improved the indicators in patients with weakened inspiratory muscle, but had modest effects in those with normal inspiratory muscle strength. Thus, we suggested that CPAP may be more beneficial in terms of respiratory mechanics in patients with inspiratory muscle weakness. In addition to weaker inspiratory muscle strength, these patients had worse lung function along with PEEPi and Raw, and higher work of breathing, although the differences were not significant $(\mathrm{P}>0.05)$. The patients with weakened inspiratory muscle would experience diaphragm fatigue and low efficiency in the NRD. The application of CPAP could relieve diaphragmatic fatigue and increase the efficiency of NRD.

However, DPH was more likely to occur in patients with weakened respiratory muscle because of the worsening tension-length relationship in a fatigued diaphragm, which results in increased NRD. CPAP had slight effects in patients with normal respiratory muscle, for their respiratory muscle strength $\left(98.46 \pm 12.01 \mathrm{cmH}_{2} \mathrm{O}\right)$ was similar to healthy people.

One major limitation was that this research was a pilot study of physiological mechanisms about CPAP in COPD patients without respiratory failure. As COPD is a complicated airway disorder, further trials are necessary to evaluate the inconclusive long-term effects of CPAP with a large sample size and randomized control designed. Despite this, we elucidated the effects of CPAP on respiratory mechanics and NRD in non-RF-complicated COPD patients, which could offer evidence for early intervention with CPAP in COPD patients to delay the onset of respiratory failure.

In addition, we also included Ve/RMS to evaluate the efficiency of NRD. This would be more meaningful than NRD itself to establish a reasonable CPAP level. The effects of CPAP compared between patients with different inspiratory muscle strength would help physicians to focus on
CPAP for patients with weakened inspiratory muscle strength and on working up an individualized CPAP strategy.

\section{Conclusions}

CPAP may improve PEEPi, Raw, and work of breathing of breathing, but easily increases DPH in COPD patients without respiratory failure. Improvements in these indices are weakened at higher pressure levels. CPAP also improve the respiratory pattern and increase the efficiency of the neural drive. CPAP may be more susceptible to affect the respiratory mechanics in patients with weakened inspiratory muscle.

\section{Acknowledgments}

The abstract of this paper was presented at the $21 \mathrm{st}$ Congress of the APSR 2016, 12-15 November 2016, Bangkok, Thailand as a poster presentation with interim findings. The poster's abstract was published in "Poster Abstracts" in Respirology: http://onlinelibrary.wiley.com/ doi/10.1111/resp.12939_15/full.

Funding: This work was funded unconditionally by Clinical Research training program of Southern Medical University (LC2016PY032), Medical Scientific Research Foundation of Guangdong Province (A2019425), the Guangzhou Innovation and Entrepreneurship Education Project of Universities (201709T26), and the Scientific Research startup program of Southern Medical University (PY2018N046), Medical Scientific Research Foundation of Guangdong Province (B2018057)

\section{Footnote}

Conflicts of Interest: The authors have no conflicts of interest to declare.

Ethical Statement: The authors are accountable for all aspects of the work in ensuring that questions related to the accuracy or integrity of any part of the work are appropriately investigated and resolved. The study protocol was in accordance with the Declaration of Helsinki, and approved by the Zhujiang Hospital ethics committee, Southern Medical University. Informed consents about the study procedures were signed and obtained from all the subjects before the trial.

Open Access Statement: This is an Open Access article distributed in accordance with the Creative Commons 
Attribution-NonCommercial-NoDerivs 4.0 International License (CC BY-NC-ND 4.0), which permits the noncommercial replication and distribution of the article with the strict proviso that no changes or edits are made and the original work is properly cited (including links to both the formal publication through the relevant DOI and the license). See: https://creativecommons.org/licenses/by-nc-nd/4.0/.

\section{References}

1. Vogelmeier CF, Criner GJ, Martinez FJ, et al. Global Strategy for the Diagnosis, Management and Prevention of Chronic Obstructive Lung Disease 2017 Report: GOLD Executive Summary. Respirology 2017;22:575-601.

2. Peng $X$, Huang $M$, Zhao $W$, et al. Delayed diagnosis is associated with greater disease severity of chronic obstructive pulmonary disease. Nan Fang Yi Ke Da Xue Xue Bao 2018;38:1448-52.

3. Pedersen OF, Butler JP. Expiratory flow limitation. Compr Physiol 2011;1:1861-82.

4. Spruit MA, Singh SJ, Garvey C, et al. An official American Thoracic Society/European Respiratory Society statement: key concepts and advances in pulmonary rehabilitation. Am J Respir Crit Care Med 2013;188:e13-64.

5. Köhnlein T, Windisch W, Kohler D, et al. Noninvasive positive pressure ventilation for the treatment of severe stable chronic obstructive pulmonary disease: a prospective, multicentre, randomised, controlled clinical trial. Lancet Respir Med 2014;2:698-705.

6. Sun YQ, Wei Q, Liu Z. Efficacy of Continuous Positive Airway Pressure in the Treatment of Chronic Obstructive Pulmonary Disease Combined With Respiratory Failure. Am J Ther 2016;23:e439-50.

7. O'Donoghue FJ, Catcheside PG, Jordan AS, et al. Effect of CPAP on intrinsic PEEP, inspiratory effort, and lung volume in severe stable COPD. Thorax 2002;57:533-9.

8. CPAP reduces risk of death in people with COPD and sleep apnea. R I Med J (2013) 2013;96:50.

9. Ding N, Zhang $X$. Transvenous phrenic nerve stimulation, a novel therapeutic approach for central sleep apnea. J Thorac Dis. 2018; 10: 2005-10.

10. Pandit JJ, Mohan RM, Paterson ND, et al. Cerebral blood flow sensitivities to $\mathrm{CO} 2$ measured with steady-state and modified rebreathing methods. Respir Physiol Neurobiol. 2007;159:34-44.

11. Goldberg P, Reissmann H, Maltais F, et al. Efficacy of noninvasive CPAP in COPD with acute respiratory failure. Eur Respir J 1995;8:1894-900.
12. Miro AM, Shivaram U, Hertig I. Continuous positive airway pressure in COPD patients in acute hypercapnic respiratory failure. Chest 1993;103:266-8.

13. Rochester DF, Bettini G. Diaphragmatic blood flow and energy expenditure in the dog. Effects of inspiratory airflow resistance and hypercapnia. J Clin Invest 1976;57:661-72.

14. Rossi A, Aisanov Z, Avdeev S, et al. Mechanisms, assessment and therapeutic implications of lung hyperinflation in COPD. Respir Med 2015;109:785-802.

15. Zeng GS, Chen LC, Fan HZ, et al. The relationship between steps of 6MWT and COPD severity: a crosssectional study. Int J Chron Obstruct Pulmon Dis 2018;14:141-8.

16. Qin YY, Li RF, Wu GF, et al. Effect of tiotropium on neural respiratory drive during exercise in severe COPD. Pulm Pharmacol Ther. 2015;30:51-6.

17. Li Y, Li YH, Li S, et al. Efficiency of neural respiratory drive for the assessment of bronchodilator responsiveness in patients with chronic obstructive pulmonary disease: an exploratory study. J Thorac Dis 2016;8:958-65.

18. Murphy PB, Kumar A, Reilly C, et al. Neural respiratory drive as a physiological biomarker to monitor change during acute exacerbations of COPD. Thorax 2011;66:602-8.

19. Maltais F, Reissmann H, Gottfried SB. Pressure support reduces inspiratory effort and dyspnea during exercise in chronic airflow obstruction. Am J Respir Crit Care Med 1995;151:1027-33.

20. Polkey MI, Kyroussis D, Mills GH, et al. Inspiratory pressure support reduces slowing of inspiratory muscle relaxation rate during exhaustive treadmill walking in severe COPD. Am J Respir Crit Care Med 1996;154:1146-50.

21. Cheeseman M, Revelette WR. Phrenic afferent contribution to reflexes elicited by changes in diaphragm length. J Appl Physiol (1985) 1990;69:640-7.

22. Reid MB, Banzett RB, Feldman HA, et al. Reflex compensation of spontaneous breathing when immersion changes diaphragm length. J Appl Physiol (1985) 1985;58:1136-42.

23. Banzett RB, Inbar GF, Brown R, et al. Diaphragm electrical activity during negative lower torso pressure in quadriplegic men. J Appl Physiol Respir Environ Exerc Physiol 1981;51:654-59.

24. Green M, Mead J, Sears TA. Muscle activity during chest wall restriction and positive pressure breathing in man. Respir Physiol 1978;35:283-300.

25. Jolley CJ, Luo YM, Steier J, et al. Neural respiratory 
drive in healthy subjects and in COPD. Eur Respir J 2009;33:289-97.

26. Qin YY, Steier J, Jolley C, et al. Efficiency of neural drive during exercise in patients with COPD and healthy subjects. Chest 2010;138:1309-15.

27. Luo YM, Lyall RA, Harris ML, et al. Effect of lung volume on the oesophageal diaphragm EMG assessed by magnetic phrenic nerve stimulation. Eur Respir J 2000;15:1033-38.

28. Jolley CJ, Luo YM, Steier J, et al. Neural respiratory drive and breathlessness in COPD. Eur Respir J 2015;45:355-64.

Cite this article as: Wang $\mathrm{K}$, Liang ZY, Wang XL, Li Y, Lu YR, Liu JF, Li JH, Xu LM, Chen GQ, Chang P, Cen ZR, Chen $\mathrm{X}$. Continuous positive airway pressure improves respiratory mechanics and efficiency of neural drive in stable COPD: an exploratory study. J Thorac Dis 2020;12(3):626-638. doi: 10.21037/jtd.2019.12.120
29. $\mathrm{Xu} \mathrm{W,} \mathrm{Li} \mathrm{R,} \mathrm{Guan} \mathrm{L,} \mathrm{et} \mathrm{al.} \mathrm{Combination} \mathrm{of} \mathrm{inspiratory}$ and expiratory muscle training in same respiratory cycle versus different cycles in COPD patients: a randomized trial. Respir Res 2018;19:225.

30. Wang K, Zeng GQ, Li R, et al. Cycle ergometer and inspiratory muscle training offer modest benefit compared with cycle ergometer alone: a comprehensive assessment in stable COPD patients. Int J Chron Obstruct Pulmon Dis 2017;12:2655-68. 